\title{
Porous Wood Decorated with Gold Nanoparticles as Flow-through Membrane Reactor for Catalytic Hydrogenation of Methylene Blue and 4-Nitrophenol
}

\section{Yuanyuan $\mathrm{Yu}$}

Guangxi University

Qingtong Zhang

Guangxi University

Mingchao Chi

Guangxi University

Hongrui Jiang

Guangxi University

Xi Liu

Guangxi Bossco Environmental Protection Technology Co. Ltd.

\section{Shuangfei Wang}

Guangxi University

Douyong Min ( $\nabla$ min.douyong@outlook.com )

GuangXi University https://orcid.org/0000-0003-0842-1355

\section{Research Article}

Keywords: Wood, Lignin, Gold nanoparticle, Catalytic degradation, Wastewater treatment

Posted Date: March 1st, 2021

DOl: https://doi.org/10.21203/rs.3.rs-230687/v1

License: (c) (i) This work is licensed under a Creative Commons Attribution 4.0 International License.

Read Full License 
1 Porous wood decorated with gold nanoparticles as flow-through membrane

2 reactor for catalytic hydrogenation of methylene blue and 4-nitrophenol

3 Yuanyuan $\mathrm{Yu},{ }^{\mathrm{a}, \mathrm{c}}$ Qingtong Zhang, ${ }^{\mathrm{a}, \mathrm{c}}$ Mingchao Chi, ${ }^{\mathrm{a}, \mathrm{c}}$ Hongrui Jiang, ${ }^{\mathrm{a}} \mathrm{Xi}$ Liu, Shuangfei Wang, ${ }^{\mathrm{a}, \mathrm{b}, \mathrm{c}}$ and Douyong Min ${ }^{\mathrm{a}, \mathrm{c}^{*}}$

a. College of Light Industry and Food Engineering, Guangxi University, Nanning 530004, PR China

b. Guangxi Bossco Environmental Protection Technology Co., Ltd, Nanning 530007, PR China

c. Guangxi Key Laboratory of Clean Pulp \& Papermaking and Pollution Control,

24 The corresponding author's email: mindouyong@gxu.edu.cn 
Abstract: In this study, gold nanoparticles (Au NPs) were decorated into Paulownia

26 Sieb. et Zucc. chip. Lignin, as one main component of wood, contains the reducing 27 groups e.g. hydroxyl, carbonyl and aldehyde groups. Under sunlight irradiation, Au (III) 28 diffused into wood was in situ reduced by lignin to form gold nanoparticles. Therefore, 29 the $\mathrm{Au} \mathrm{NPs/Wood} \mathrm{was} \mathrm{successfully} \mathrm{fabricated} \mathrm{by} \mathrm{this} \mathrm{facile} \mathrm{and} \mathrm{green} \mathrm{procedure.}$ 30 Meanwhile, the three-dimensional interpenetrating network of wood prevented the 31 aggregation of Au NPs which retained its catalytic activity. Methylene blue and 432 nitrophenol were adopted as model organic contaminants to evaluate the catalytic 33 hydrogenation ability of the Au NPs/Wood. The analyses of XRD, SEM, ICP-MS and 34 XPS indicated that Au NPs were successfully immobilized in wood chip. The 35 degradation results revealed that the Au NPs/Wood has excellent catalytic activity for 36 methylene blue and 4-nitrophenol hydrogenation under batchwise and continuous flow 37 process. Meanwhile, the Au NPs/Wood also exhibited excellent recyclability. The 38 hydrogenation efficiency of MB and 4-NP still reaches more than $90 \%$ after 8 cycles. 39 This study provides a new solution for green and low-cost fabrication of Au NPs/Wood 40 which has broad application prospects in wastewater treatment.

41 Keywords: Wood; Lignin; Gold nanoparticle; Catalytic degradation; Wastewater 42 treatment 


\section{Introduction}

At present, nanostructured catalysts with high specific surface area and surface energy have been widely studied by researchers (Sharma et al., 2015). Among them, noble metal nanoparticles have high activity as heterogeneous catalysts in many liquidphase reactions (Ji et al., 2015; Zahmakiran and Ozkar, 2011), especially in the catalytic conversion or decomposition of organic pollutants such as nitro-group compounds and dyes (Shultz et al., 2019). Gold nanoparticle (Au NPs) with high specific surface area and characteristics of less likelihood of metal leaching and self-poisoning has attracted much attention due to its desirable chemical catalytic ability (Alba-Molina et al., 2019; Hassinen et al., 2015).

Nevertheless, there are still two major challenges limiting the application of $\mathrm{Au}$ NPs. First challenge is related to the easy agglomeration of Au NPs in aqueous solution, which reduces the contact area between Au NPs and target pollutants, therefore the catalytic performance of Au NPs will be seriously inhibited (Massaro et al., 2019; Zhang et al., 2020). In order to maintain the dispersibility of Au NPs, it is usually fixed on solid support (such as silica, metal oxides and polymers), which can prevent Au NPs from aggregation and ensure high catalytic activity (Gualteros et al., 2018; Kong et al., 2020; Singh et al., 2019; Wang et al., 2019). However, in some chemical environments with high or low $\mathrm{pH}$, the stability of the above solid carrier will be affected, resulting in problems such as the dissolution of the carrier or the inability to obtain uniform distribution of Au NPs (Quast et al., 2016; Saini et al., 2010). Another challenge comes from the chemical reduction reaction adopted for Au NPs preparation. During this process, the reducing agents and the stabilizing agents are extensively used (Al-Johani et al., 2017; Alba-Molina et al., 2019). From the perspective of the environment and human health, these chemical reagents are toxic and harmful, and the synthesis process has many steps and low efficiency. In addition, the complete separation of Au NPs from the reaction system is also a huge challenge. All of these have brought difficulties to the extensive application of Au NPs (Raveendran et al., 2003).

1 Therefore, it is the main research of basic application of Au NPs to find high 
stability carrier and realize green synthesis method. Wood is a natural three-dimensional porous material with unique microstructure (Liu et al., 2019), which can be used as a carrier to construct functional composite materials. Lignin, one of the main components of wood, contains many functional groups, such as hydroxyl group, carbonyl group and aldehyde group (Chen et al., 2020). These functional groups can be used as reducing functional groups to synthesize metal nanoparticles (Luo et al., 2017; Wang et al., 2016). Furthermore, the orderly channel structure of wood can pump water and nutrients from the root to the crown under the sunlight irradiation (Liu et al., 2019; Zhu et al., 2018). Therefore, when the wood comes into contact with the metal salt solution under sunlight irradiation, the metal ions will be pumped out from the bottom of the solution and diffused in the middle channel, and reduced to metal nanoparticles by lignin. Paulownia is a kind of fast-growing wood, which is distributed in various regions of China (Ates et al., 2008). It is a natural material with honeycomb units, high strength/stiffness weight ratio and high grade value (Janjić and Janjić, 2019). Therefore, Paulownia decorated with gold nanoparticles can be used as the membrane for wastewater treatment.

In this work, the Au NPs/Wood was fabricated by a green and simple method, and its catalytic activity was respectively tested by batchwise and continuous flow reaction. The Au NPs were in situ reduced and immobilized in the cavity structure of Paulownia by one-step irradiation of wood immersing in $\mathrm{Au}$ (III) solution. Under the conditions of batchwise and continuous flow reaction, the catalytic performance of gold nanoparticles immobilized in the wood chip was investigated with MB and 4-NP as the organic pollutant models.

\section{Experimental section}

\subsection{Materials and chemical regents}

The wood (Paulownia Sieb. et Zucc.) used in this study was obtained from the local timber market (Nanning China). Gold chloride acid $\left(\mathrm{AuCl}_{3} \cdot \mathrm{HCl} \cdot 4 \mathrm{H}_{2} \mathrm{O}, \mathrm{HAuCl}_{4}\right.$, $\geq 99 \%$ ) and 4-nitrophenol (4-NP, $\geq 99 \%$ ) were purchased from Shanghai McLean Biochemical Technology Co., Ltd (Shanghai, China). Anhydrous ethanol $\left(\mathrm{CH}_{3} \mathrm{CH}_{2} \mathrm{OH}\right.$, 
$101 \geq 99 \%$ ) and methylene blue (MB) and were purchased from Tianjin Zhiyuan Chemical

102 Reagent Co., LTD (Tianjin China). Sodium borohydride $\left(\mathrm{NaBH}_{4}, \geq 99 \%\right.$ ) was

103 purchased from Sigma Aldrich Chemical Company (Shanghai China). The ultrapure

104 water was used for all experiments (Milli-Q purification system, Darmstadt Merck

105 Company, Germany).

$106 \quad 2.2$ Preparation of Au NPs/Wood

107 The wood was cut perpendicular to the growth direction into slices $(25 \times 25 \times 1$

$108 \mathrm{~mm}^{3}$ ). The wood slices were extracted with water at $85^{\circ} \mathrm{C}$ for $18 \mathrm{~h}$ (water was replaced

109 at an interval of $3 \mathrm{~h}$ ) to remove soluble impurities and then the samples were air dried

110 overnight. Thereafter, the slice was immersed into $20 \mathrm{~mL} \mathrm{HAuCl}_{4}$ solution $(1 \mathrm{mM})$ for

$1113 \mathrm{~h}$ under the sunlight irradiation (CEAULIGHT, CEL-WLAX500). The products were

112 ultrasonic washed with ultrapure water for 30 min several times to remove the unreacted

113 chemicals and unfixed Au NPs. Eventually, the Au NPs/Wood was obtained after $8 \mathrm{~h}$

114 vacuum drying.

\section{$115 \quad 2.3$ Characterization}

116 The surface morphology of the wood and Au NPs/Wood were characterized by

117 scanning electron microscope (SEM, Hitachi SU8000 Series). The surface components

118 of the samples were determined by X - ray electron spectroscopy (XPS, ESCALAB 250

119 XI+, Thermo Fisher Scientific, U.S.A.). The gold nanoparticles in the wood were

120 characterized by solid ultraviolet visible spectrophotometer (UV-Vis, Specond plus 50,

121 Analytikjena, Germany) at the spectrum of 400-900 nm. The crystal nanostructure of

$122 \mathrm{Au}$ loaded on the wood was revealed by 2200 X-ray diffraction (XRD,

123 SMARTLAB3KW, Rigaku, Japan), operating with a $\mathrm{Cu}-\mathrm{K} \alpha$ radiation $(\lambda=1.54 \AA)$. The

124 Au content of the Au NPs/Wood was quantified by inductively coupled plasma mass 125 spectrometry (Agilent ICP-MS7800, U.S.A.).

$126 \quad 2.4$ Catalytic performance of Au NPs/Wood

127 The $\mathrm{MB}(30 \mathrm{mg} / \mathrm{L}), 4-\mathrm{NP}(0.2 \mathrm{mM})$ and $\mathrm{NaBH}_{4}(50 \mathrm{mM})$ solutions were prepared

128 in ice water bath, respectively. The mixture prepared with equal volume proportion of 129 the $\mathrm{MB}$ and $\mathrm{NaBH}_{4}$ solutions was used for the catalytic degradation of MB (Qin, L. et 
al., 2019). Subsequently, the wood and Au NPs/Wood were immersed in $30 \mathrm{~mL}$ mixture

131 at room temperature with magmatic stirring. The liquor was collected at the desired

132 time intervals and its absorbance from $400-800 \mathrm{~nm}$ was characterized by UV-Vis

133 spectroscopy. The absorbance changes according to the reaction time were quantified

134 by UV-Vis at $665 \mathrm{~nm}$. As a comparison, the Au NPs isolated from the Au NPs/Wood by

135 ultrasonic treatment for $2 \mathrm{~h}$ was also applied to catalytically degrade the mixture. The

$136 \mathrm{Au}$ NPs/Wood, wood and Au NPs were respectively used as the catalyst to complete

137 the reaction. The mixture prepared with equal volume proportion of the 4-NP and

$138 \mathrm{NaBH}_{4}$ solutions was used for the catalytic degradation of 4-NP. The absorbance in the

139 range of 200-600 nm was characterized by UV-Vis spectroscopy, and the hydrogenation

140 efficiency of 4-NP was evaluated by the change of absorbance at $400 \mathrm{~nm}$. The reduction

141 efficiency of MB and 4-NP was calculated using the following equation:

142 Conversion $(\%)=\left(C_{0}-C_{t}\right) / C_{0} * 100 \%=\left(A_{0}-A_{t}\right) / A_{0} * 100 \%$

143 Where $C_{0}$ and $C_{t}$ are the concentration of the mixture before and after the reaction

144 respectively, and $A_{0}$ and $A_{t}$ are the corresponding absorbance (Guo et al., 2019).

145 The Au NPs/Wood placed on the sand core filter was used for the continuous flow

146 degradation which was conducted at $0.015 \mathrm{MPa}$. Before the reaction, the Au NPs/Wood

147 was immersed in the MB solution to reach the equilibrium to eliminate the adsorption

148 interference (Liu et al., 2017). Thereafter, the mixture of $\mathrm{MB}$ and $\mathrm{NaBH}_{4}$ was filtered

149 through the $\mathrm{Au} \mathrm{NPs/Wood} \mathrm{to} \mathrm{complete} \mathrm{the} \mathrm{continuous} \mathrm{flow} \mathrm{degradation.} \mathrm{The} \mathrm{flow}$

150 degradation of 4-NP was conducted with the same procedure. As a comparison, the

151 wood chip was also used to conduct the continuous flow degradation. The factors

152 including the Au NPs/Wood layers, the concentration of contaminants, and the water

153 flux were evaluated. As for the evaluation of recyclability, the Au NPs/Wood was

154 recovered by washing with deionized water followed with ethanol for the subsequent

155 reaction.

\section{3. Results and Discussion}

$157 \quad 3.1$ Characterizations

158 Under the sunlight irradiation, Au (III) was diffused into the wood and reduced in 
situ by lignin to form Au NPs. Fig. 1a shows that the wood color changed from brown yellow to purple due to the surface plasmon effect of Au NPs depositing on the surface of wood cell wall (Amendola et al., 2017). Fig. 1b indicates that Au NPs was uniformly deposited throughout the wood slice. SEM-EDS characterization observed that the wood cell wall surface was uniformly loaded with Au NPs (Fig. 1c-f). The high resolution SEM image (Fig. 1g) confirmed that Au NPs immobilized uniformly on the wood cell wall surface without aggregation which retained their catalytic ability. Furthermore, the gold content of the sample was quantified as $1.4 \mathrm{wt} \%$ by ICP-MS. The unique three-dimensional porous structure was maintained in the Au NPs/Wood. A large number of honeycomb like units and channels were connected with the perforated plates containing nano size pores (Fig. 1h). Fig. 1i confirms that nano size pores were identified in the perforated plates. Fig. $1 \mathrm{j}$ demonstrates that the vessels connected with the perforated plates can be used as channels for transferring water and nutrients in the wood. All of these characteristics of the wood ensured that the Au NPs/Wood can be used as an ideal catalytic membrane for wastewater treatment.
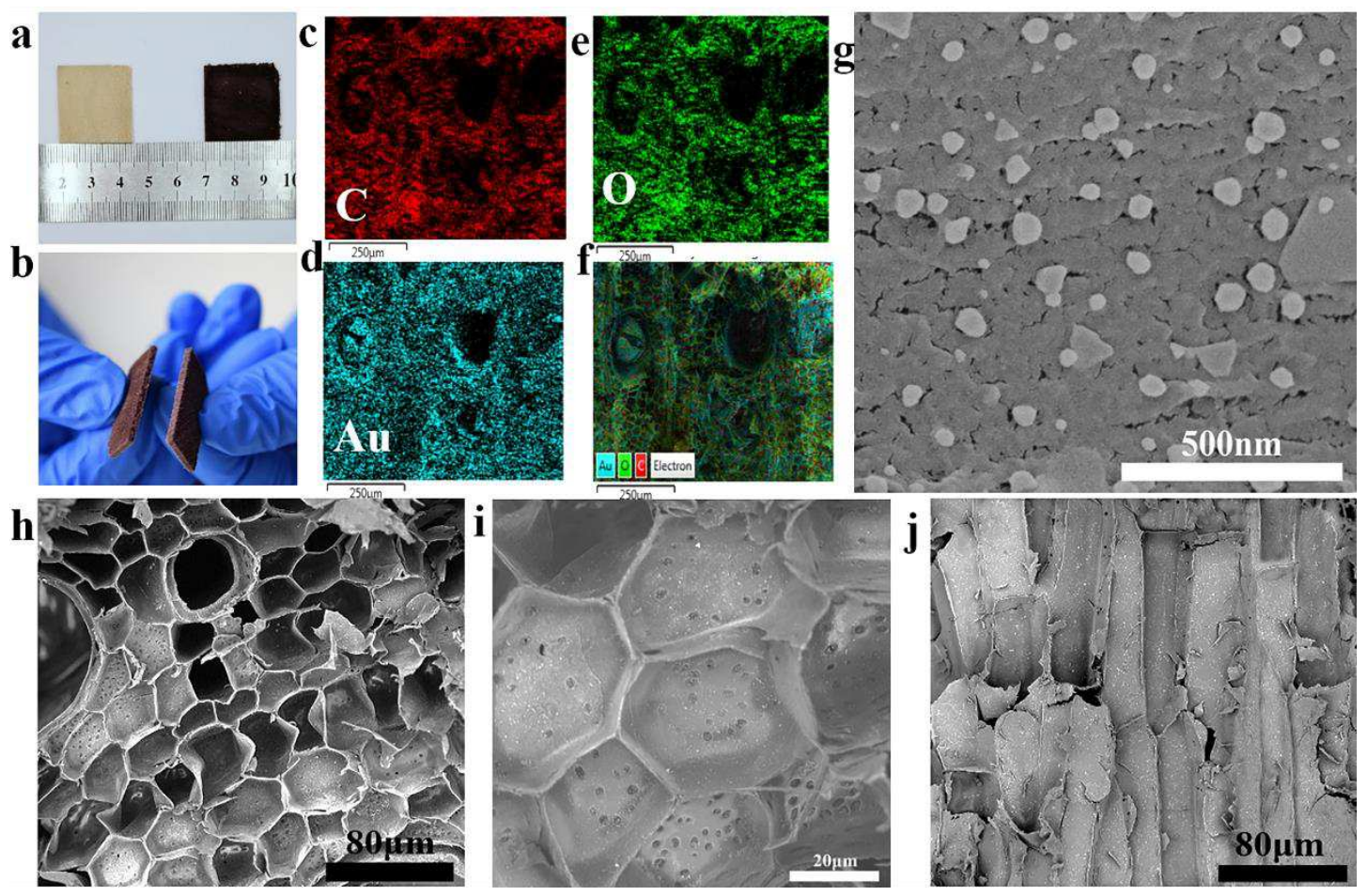

Fig. 1 Photos of (a) the wood and (b) the Au NPs/Wood. (c)-(f) C, O, Au elemental mapping of a transverse section of the Au NPs/Wood. (g) SEM image of Au NPs distributing on the wood. (h-j) SEM images of the Au NPs/Wood. 
$179 \mathrm{Au}$ NPs/Wood (Fig. 2a) was attributed to the surface plasma resonance phenomenon of

$180 \mathrm{Au}$ NPs (Cabreira and Camilo, 2020; Haiss et al., 2007; Luty-Błocho et al., 2011),

181 which further proved that Au NPs was successfully decorated in the wood. As for the

182 XRD characterization (Fig. 2b), the diffraction peaks at $21.6^{\circ}$ and $34.3^{\circ}$ were

183 respectively assigned to the reflections from the (200) and (004) planes of cellulose.

184 The XRD peaks of Au NPs/Wood were $38.1^{\circ}, 44.3^{\circ}, 64.7^{\circ}$ and $77.6^{\circ}$, which were

185 attributed to surface reflections of $\mathrm{Au}$ (110), (200), (220) and (311), respectively

186 (JCPDS 04-0784) (Ju et al., 2015; Liu et al., 2018). The chemical composition of the

$187 \mathrm{Au} \mathrm{NPs/Wood} \mathrm{was} \mathrm{characterized} \mathrm{by} \mathrm{XPS.} \mathrm{Fig.} \mathrm{2c} \mathrm{shows} \mathrm{that} \mathrm{the} \mathrm{peaks} \mathrm{assigned} \mathrm{to} \mathrm{Au}$

188 4f, Au 4d were identified from the Au NPs/Wood, while only the peaks assigned to C

189 1s and $\mathrm{O} 1 \mathrm{~s}$ were identified in the wood. As shown in Fig. $2 \mathrm{~d}, \mathrm{Au} 4 \mathrm{f}_{5 / 2}$ and $4 \mathrm{f}_{7 / 2}$ peaks

190 were observed at $87.6 \mathrm{eV}$ and $83.8 \mathrm{eV}$, respectively, which confirmed the zero valence

191 state of gold on the cell wall surface (Kong et al., 2009; Zhang et al., 2011).
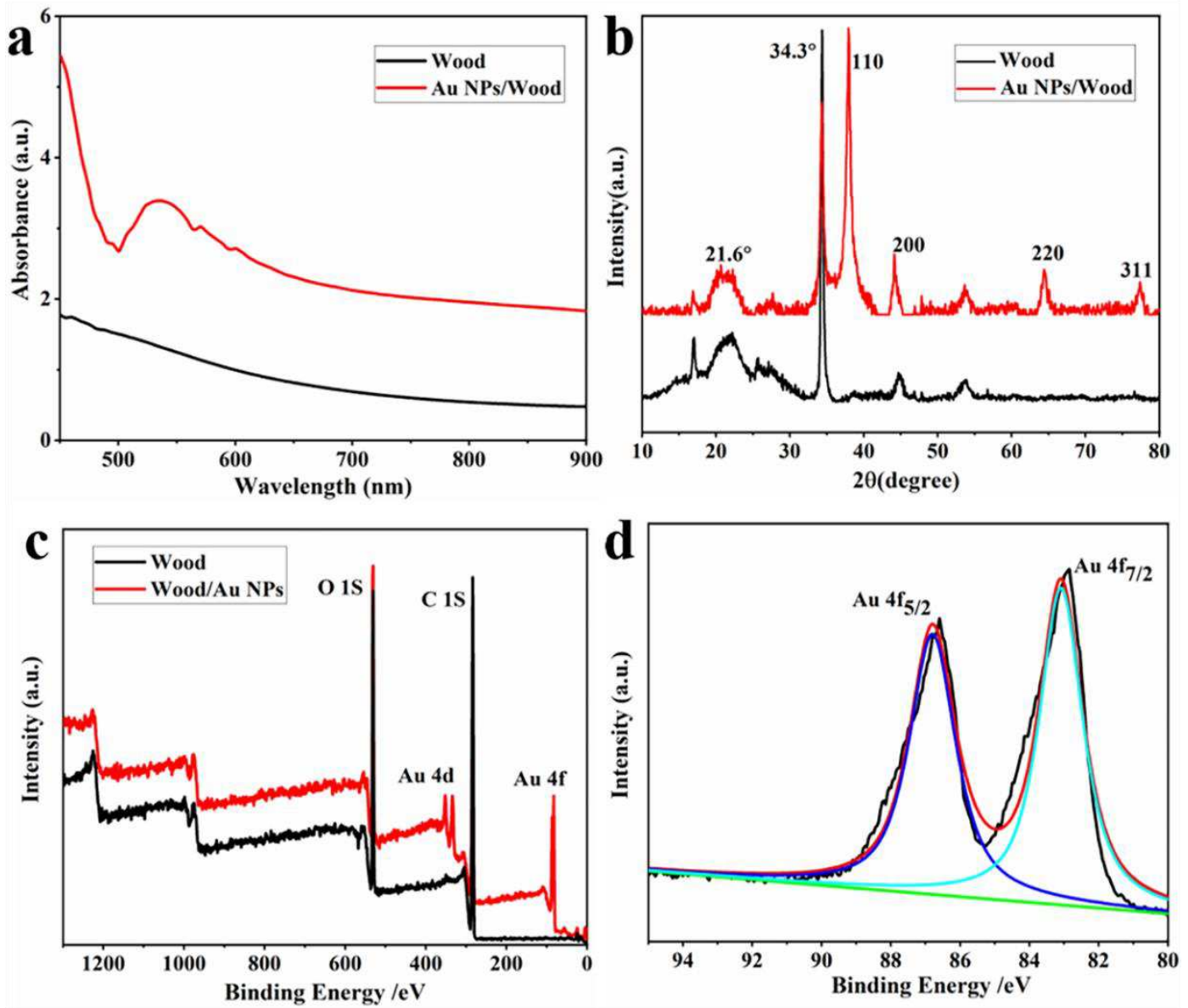

192 
Fig. 2 (a) UV-Vis spectrum of the wood and the Au NPs/Wood. (b) XRD patterns of the wood and the Au NPs/Wood. (c) XPS of the wood and the Au NPs/Wood, and (d) high-resolution XPS spectra of $\mathrm{Au} 4 \mathrm{f}$ in the $\mathrm{Au} \mathrm{NPs} /$ Wood.

\subsection{Catalytic activity of Au NPs/Wood}

$\mathrm{NaBH}_{4}\left(\mathrm{E}^{\circ}=-1.33 \mathrm{~V}\right)$ is reported to be thermodynamically feasible to reduce 4$\mathrm{NP}\left(\mathrm{E}^{\circ}{ }_{4-\mathrm{NP} / 4-\mathrm{AP}}=0.76 \mathrm{~V}\right)$ and $\mathrm{MB}\left(\mathrm{E}^{\circ} \mathrm{MB} / \mathrm{LMB}=-0.21 \mathrm{~V}\right)($ Neal et al., 2019), but the reaction is not favorited by the kinetics due to the large difference of their standard electrode potentials between $\mathrm{NaBH}_{4}$ and the pollutant model (Yan et al., 2018). As an active electron transfer medium, Au NPs possesses an appropriate redox potential and plays a critical role in the reaction by helping to overcome the kinetic barrier by facilitating electron transfer from the donor $\left(\mathrm{NaBH}_{4}\right)$ to the recipient $(\mathrm{MB} / 4-\mathrm{NP})$ (Gupta et al., 2011).

\subsubsection{Batchwise catalytic degradation}

The UV-Vis absorbance at $665 \mathrm{~nm}$ decreased slightly with the reaction time as the wood slice was immersed in the mixture (Fig. 3a), which was attributed to a little adsorption of MB by the wood. As a comparison, the absorbance at $665 \mathrm{~nm}$ was little detected after $21 \mathrm{~min}$ immersion (Fig. 3b), indicating that the Au NPs/Wood had an effective catalytic performance on the reduction of MB. According to the previous report, the reduction process can be described as a quasi-first-order kinetic process (Ramirez et al., 2017). Thus, the reaction rate constant (k) can calculated to evaluate the catalyst's performance according to the following equation:

$$
\ln \left(C_{t} / C_{0}\right)=\ln \left(A_{t} / A_{0}\right)=-k t
$$

Where $C_{0}$ and $C_{t}$ are the concentration of the contaminant at the initial stage and at the reaction time $\mathrm{t}(\mathrm{min})$, respectively, $A_{0}$ and $A_{t}$ are the corresponding absorbance, $\mathrm{k}$ is the reaction rate constant.

Fig. $3 \mathrm{c}$ shows the quasi-first-order kinetics between the reactants, i.e. the reaction rate constant $\mathrm{k}$ was calculated from the linear relationship between $\ln \left(\mathrm{C}_{t} / \mathrm{C}_{0}\right)$ and reaction time. The catalytic reaction rate $\mathrm{k}$ of wood chips for $\mathrm{MB}$ and $\mathrm{NaBH}_{4}$ was calculated to be $0.008 \mathrm{~min}^{-1}$, and the $\mathrm{k}$ value for $\mathrm{MB}$ catalytic reduction using the $\mathrm{Au}$ NPs/Wood was calculated to be $0.162 \mathrm{~min}^{-1}$. It can be seen from Table 1 that the 
223 catalytic activity of Au NPS /Wood is comparable to some extent, or even higher than

224 that of other materials supported gold nanoparticles in the catalytic reaction kinetics of 225 MB.

226 As for the catalytic reduction of 4-NP, the characteristic absorbance at the 227 wavelength of $400 \mathrm{~nm}$ displayed by UV-Vis decreased slightly with the reaction time 228 (Fig. 3d), which was attributed to the small amount of adsorption of 4-NP by wood. 229 When $\mathrm{Au} \mathrm{NPs} /$ Wood was applied to the pollutants, the UV-Vis scanning spectrum 230 showed that the characteristic peak at $400 \mathrm{~nm}$ almost disappeared after $27 \mathrm{~min}$ reaction, 231 while a new peak appeared at $298 \mathrm{~nm}$, which was the characteristic peak of 4232 aminophenol, indicating that 4-NP was reduced to 4-AP (Fig. 3e) (Aditya et al., 2015; 233 Ma et al., 2018). The results show that Au NPS /Wood has a certain catalytic potential 234 for the reduction of 4-NP. Based on the equation (1), the k values of the wood and the $235 \mathrm{Au} \mathrm{NPs} /$ Wood for mixture were calculated as $0.011 \mathrm{~min}^{-1}$ and $0.152 \mathrm{~min}^{-1}$, respectively 236 (Fig. 3f). It can be seen from Table 1 that Au NPS /Wood has good catalytic effect on 237 4-NP.

238 Table 1 Comparison of catalytic performance of different gold based catalysts

\begin{tabular}{cccl}
\hline Catalysts & Contaminant & K value $\left(\mathrm{min}^{-1}\right)$ & \multicolumn{1}{c}{ References } \\
\hline $\mathrm{Au} \mathrm{NPs}$ & $\mathrm{MB}$ & 0.0118 & (Kumar et al., 2019) \\
$\mathrm{Au} / \mathrm{KNbO}_{3}$ & $\mathrm{MB}$ & 0.0115 & (Yan et al., 2014) \\
$\mathrm{CEL} \_$AuNPs_H $\mathrm{H}_{2} \mathrm{O}$ & $4-\mathrm{NP}$ & 0.0363 & (Cabreira and Camilo, 2020) \\
$\mathrm{Au} @$ @PZS@CCNTs & $4-\mathrm{NP}$ & 0.1072 & (Wang et al., 2014) \\
$\mathrm{Au}$ NCs/CNTs & $4-\mathrm{NP}$ & 0.2 & (Liu et al., 2017) \\
\hline
\end{tabular}



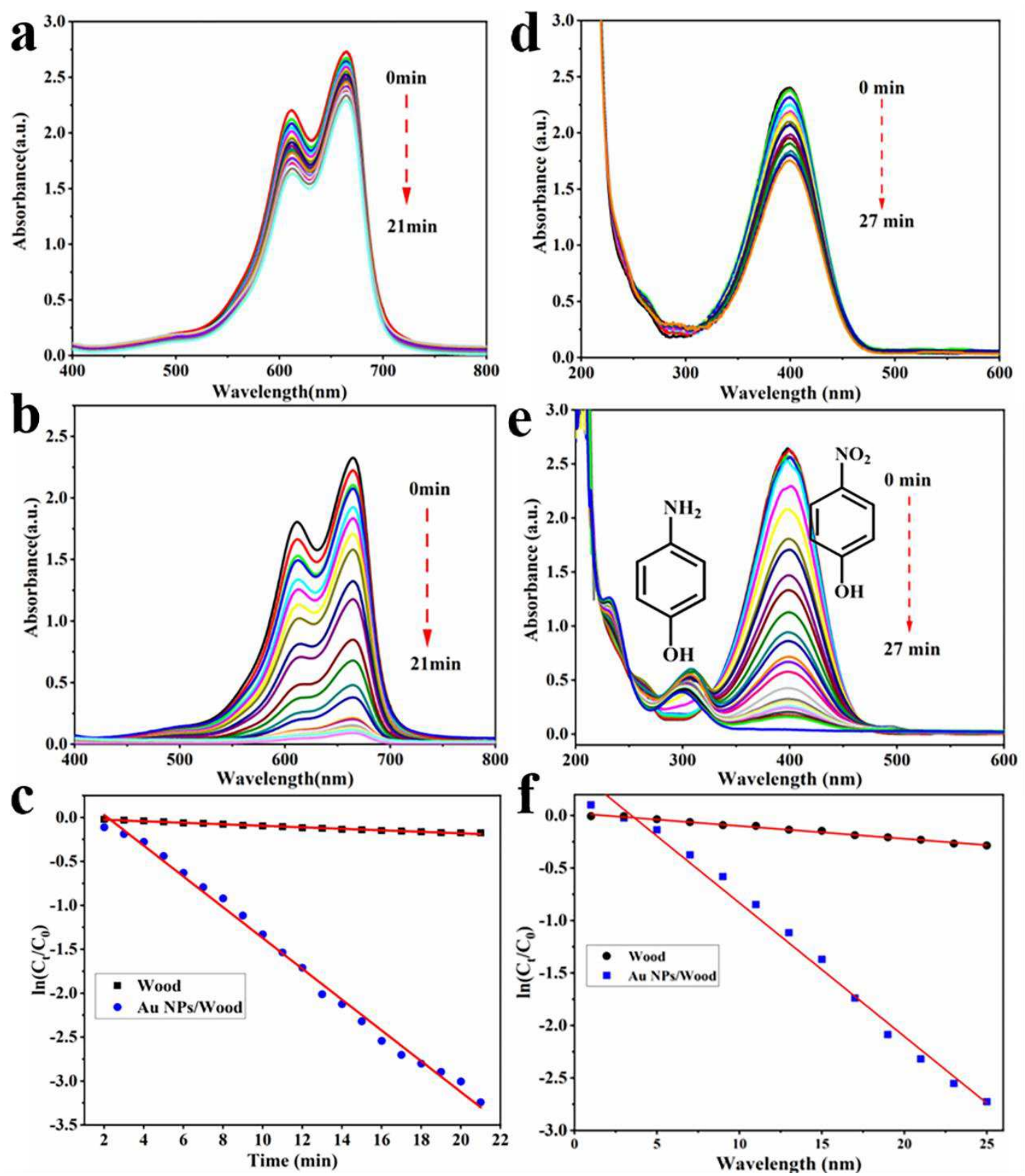

Fig. 3 The successive spectra of the mixture of $\mathrm{MB}$ and $\mathrm{NaBH}_{4}$ from 400 to $800 \mathrm{~nm}$ of (a) the wood and (b) the Au NPs/Wood. (c) The curve of $\ln \left(\mathrm{C}_{t} / \mathrm{C}_{0}\right)$ with reaction time and the quasi-first-order kinetic fitting of wood and Au NPs/Wood. The successive spectra of the mixture of $\mathrm{NaBH}_{4}$ and 4NP from 200 to $600 \mathrm{~nm}$ of (d) the wood and (e) the Au NPs/Wood. (f) The curve of $\ln \left(\mathrm{C}_{t} / \mathrm{C}_{0}\right)$ with reaction time and the quasi-first-order kinetic fitting of wood and Au NPs/Wood.

The Au NPs were isolated from the Au NPs/Wood after $2 \mathrm{~h}$ ultrasound treatment

246 at room temperature, and the characteristic color of Au NPs was observed from the 247 solution (Unal et al., 2020) (Fig. S2a). As the suspension had stood for $2 \mathrm{~h}$, the 248 precipitant was observed at the bottom of the centrifuge tube, indicating that the solo 249 Au NPs was inclined to precipitate (Fig. S2b). Therefore, the catalytic performance of 
$\mathrm{Au}$ NPs was attenuated by the precipitation. For example, the UV absorbance in the

251 range of 400-800 nm decreased little even after the mixture of $\mathrm{MB}$ and $\mathrm{NaBH}_{4}$ had 252 mixed with Au NPs for 19 min (Fig. S2c). This result verified that the decoration of $\mathrm{Au}$ 253 NPs on the surface of wood cell wall prevented their precipitation, thereby retained 254 their catalytic performance.

\section{$255 \quad$ 3.2.2 Continuous flow catalytic degradation}

256 According to the phenomena and UV-Vis measurement results observed in Fig. S2, 257 it can be inferred that the Au NPs/Wood has a promising application in continuous flow 258 catalytic reaction. Taking MB as a model pollutant, the flow catalytic ability of $\mathrm{Au}$ 259 NPs/Wood was evaluated under the vacuum filtration device shown in Fig. S4a. It can 260 be clearly seen that the initial blue solution becomes colorless after the filtration (Fig. 261 S4b). During the filtration process, the solution contacted the Au NPs in the wood, 262 therefore, the MB was catalytically reduced to LMB. When the vacuum was maintained 263 as $0.015 \mathrm{MPa}$, the impact of different layer of $\mathrm{Au} \mathrm{NPs} /$ Wood on the reduction of MB $264(30 \mathrm{mg} / \mathrm{L})$ was evaluated. The results showed that the catalytic degradation efficiency 265 of the one-layer membrane was only $22 \%$. As more layers of Au NPs/Wood were 266 applied, the removal efficiency of pollutants and the filtration time were increased. For example, the removal efficiency was obtained as $98.9 \%$ as three layers of Au NPs/Wood were applied, however the filtration time increased to $12 \mathrm{~min}$ (Fig. 4a). This result was explained by the increase of the axial tracheid perforation plate, which retained the mixture in the wood cavity, slowing down the flow velocity by forcing the solution flow

271 through more the perforated plates, and increased the contact between MB and Au NPs.

272 Therefore, the membrane composing with three layers of Au NPs/Wood were selected 273 for the next flow catalytic experiments (Thomas, 1977).

274 The impact of water fluxes on the catalytic efficiency of the Au NPs/Wood was 275 evaluated, as well. Technically, the water flux was adjusted by the vacuum. The flux of 276 water treatment can be calculated by following equation:

$$
J=V /(T \times A)
$$

278 Where $\mathrm{V}$ is the volume of solution (L), $\mathrm{T}$ is the required time for a specific volume 
solution filtering through the membrane (h), A is the effective area of the membrane

$280\left(\mathrm{~m}^{2}\right)$, and $\mathrm{J}$ is the treatment flux $\left(\mathrm{L} / \mathrm{m}^{2} \cdot \mathrm{h}\right)$ (Cheng et al., 2018).

281 Even the flux was increased to $0.973 \times 10^{3} \mathrm{~L} / \mathrm{m}^{2} \cdot \mathrm{h}$ (the corresponding vacuum was 282 of $0.015 \mathrm{MPa}$ ), the removal efficiency was still more than $95 \%$ (Fig. 4b). This result 283 was attributed to three explanations. Firstly, Au NPs, as the electron transfer between 284 nucleophilic $\mathrm{NaBH}_{4}$ and electrophilic contaminant, distribute uniformly in wood, 285 which promotes the catalytic reduction process. Secondly, the porous structure and the 286 perforated plates of the wood retain the effective contact between catalyst and reagent. 287 Finally, the low bending and arraying microchannels have good hydrophilicity and can 288 facilitate rapid sewage transport without sacrificing removal efficiency (Huang et al., 289 2016; Plaza, 2019). Moreover, the influence of MB concentrations on the catalytic 290 efficiency of the Au NPs/Wood was further analyzed. It was shown in Fig. 4c that the 291 removal of MB decreased with its concentration. It can be observed from Fig. 4c that $292 \mathrm{Au} \mathrm{NPs} /$ Wood can still show excellent degradation performance of MB in a large 293 concentration range. It should be noted that when the concentration of MB was $40 \mathrm{mg} / \mathrm{L}$, 294 the removal efficiency decreased, but still remained above 95\%. However, when the 295 concentration of $\mathrm{MB}$ increased to $60 \mathrm{mg} / \mathrm{L}$, the removal efficiency decreased 296 significantly.
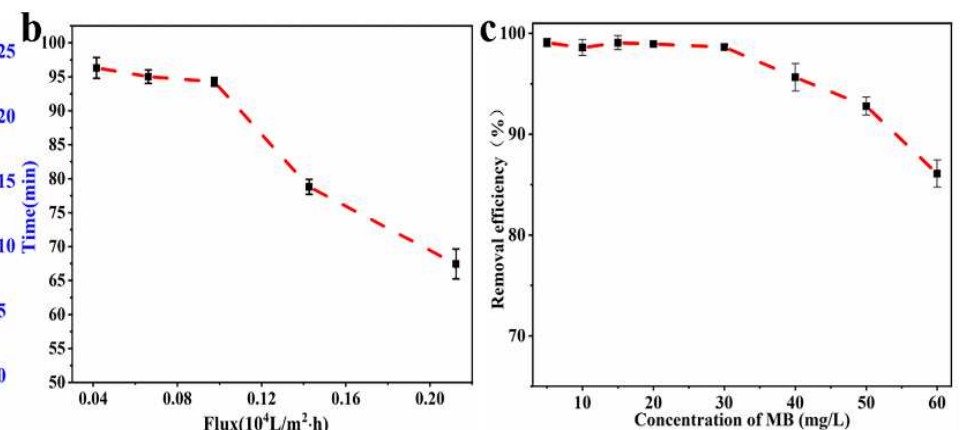

Fig. 4 (a) The layer number of Au NPs/Wood impacting on the removal efficiency and filtration time. (b) The correlation between the removal efficiency and the water flux. (c) The relationship between the removal efficiency and MB concentration.

The continuous flow catalytic reaction of 4-NP reduced to aminophenol was conducted as follows. The mixture composed with 4-NP and $\mathrm{NaBH}_{4}$ was filtered through the membrane fabricated with three layers of $\mathrm{Au}$ NPs/Wood under $0.015 \mathrm{MPa}$ vacuum. The membrane composed with the wood was used as a blank for comparison. 
305 The absorbance change during the filtration was analyzed by UV-Vis in the range of $306200-600 \mathrm{~nm}$. As shown in Fig. 5a, the peak strength at $400 \mathrm{~nm}$ after the wood filtration 307 hardly decreased, which can be interpreted as the finite adsorption of 4-NP by the wood. 308 However, After the Au NPs/Wood treatment, the characteristic peak at $400 \mathrm{~nm}$ almost 309 disappeared, meanwhile the absorption peak of 4-AP at $298 \mathrm{~nm}$ appeared, indicating 310 that 4-NP was effectively catalytically reduced to 4-AP (Fig. 5b).
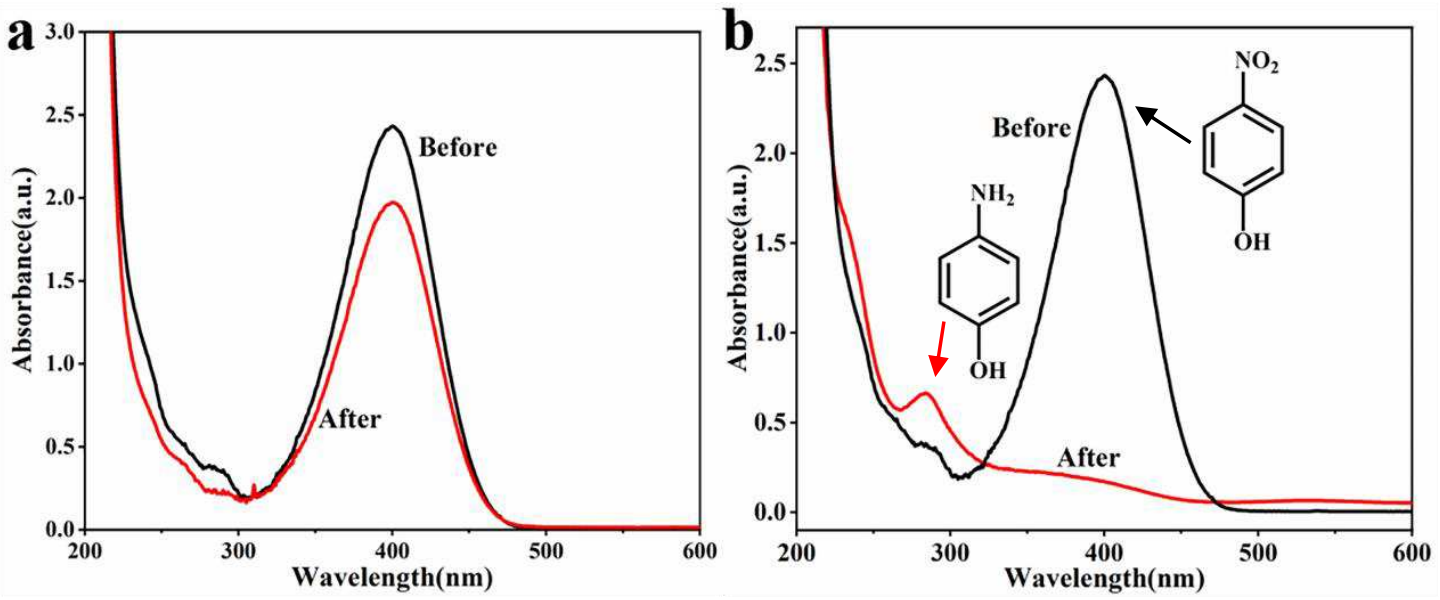

312 Fig. 5 The UV-Vis absorption change of 4-NP during the filtration through the wood (a) and the 313 Au NPs/Wood (b).

\section{$314 \quad 3.3$ Recyclability of Au NPs/Wood}

315 The recyclability is another important parameter of polyphase catalyst for the practical application. In order to investigate the recyclability of Au NPs/Wood, it was recycled eleven times for the catalytic reduction of $\mathrm{MB}$ and recycled eight times for 4-

318 NP. Fig. 6a shows that after 11 times recycle, the removal efficiency of MB by the Au 319 NPs/Wood was still over $85 \%$. The catalytic reduction efficiency of 4-NP by the Au 320 NPs/Wood remained above $85 \%$ after 8 cycles (Fig. 6b). Therefore, the Au NPs/Wood 321 had robust stability and reusability, which has important guiding significance for its 322 application in practical wastewater treatment. We speculated that there are three main reasons for the difference recyclability of Au NPs/Wood for the degradation of MB and

324 4-NP. Firstly, MB contains unsaturated bond in its molecular formula, and its induction 325 effect is stronger than that of 4-nitrophenol (Qin, Lei et al., 2019). Secondly, the 326 potential difference between $\mathrm{NaBH}_{4}\left(\mathrm{E}^{\circ}=-1.33 \mathrm{~V}\right)$ and $\mathrm{MB}\left(\mathrm{E}^{\circ}=-0.21 \mathrm{~V}\right)$ is $1.12 \mathrm{~V}$, while the redox potential difference between $\mathrm{NaBH}_{4}\left(\mathrm{E}^{\circ}=-1.33 \mathrm{~V}\right)$ and $4-\mathrm{NP}\left(\mathrm{E}^{\circ}=\right.$ 
$0.76 \mathrm{~V}$ ) is only $0.57 \mathrm{~V}$. Therefore, the catalytic reaction of $\mathrm{NaBH}_{4}$ with $\mathrm{MB}$ is much easier than with 4-NP (Jacob, 1970; Nguyen et al., 2019). Finally, the unreduced 4-NP remained in the $\mathrm{Au}$ NPs/Wood during the recycling process occupying some catalytic active sites, which retarded the catalytic reaction efficiency.
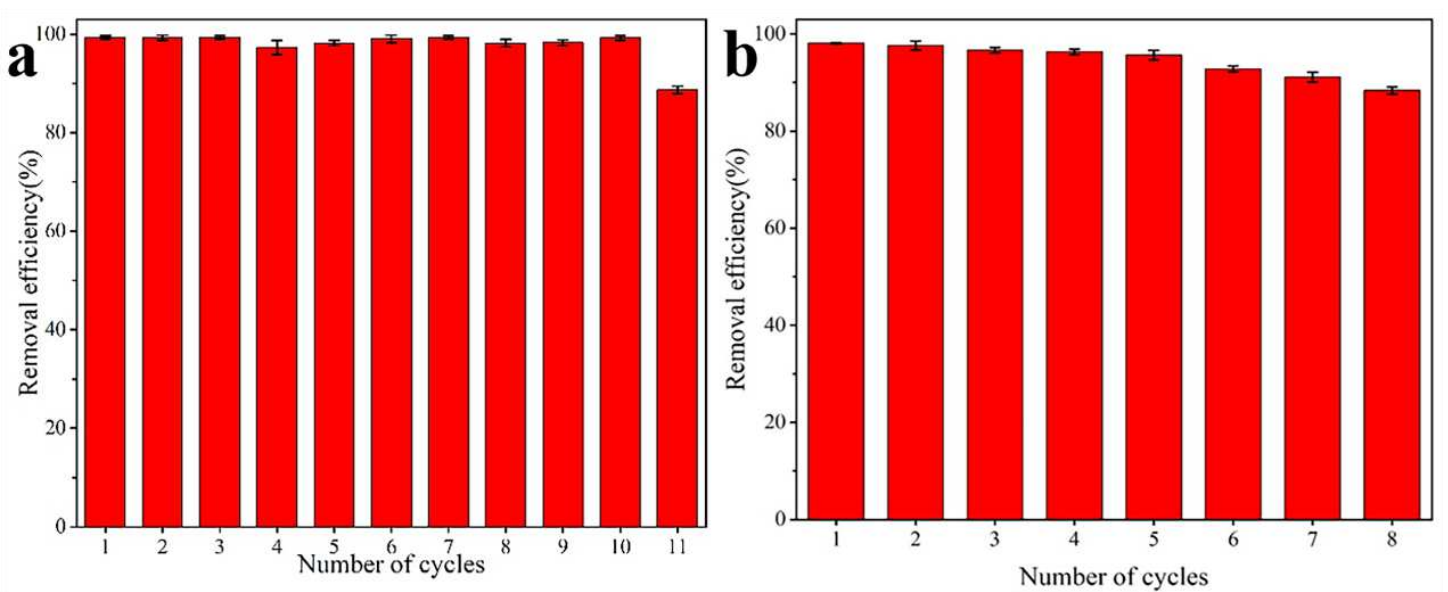

Fig. 6 The recyclability of the Au NPs/Wood for catalytic reduction of MB (a) and 4-NP (b).

\section{Conclusion}

In this work, the $\mathrm{Au}$ NPs/Wood was fabricated by a facile and green approach, which exhibited excellent catalytic activity for MB and 4-NP. Wood plays an important role in membrane preparation and catalytic reaction. Lignin in wood in situ reduced $\mathrm{Au}$ (III) to form gold nanoparticles which were anchored and stabilized on the surface of three-dimensional porous wood. Meanwhile, the perforated plate connecting among channels elongated the contacting time between the catalyst and reagent which promoted the catalytic reaction. The removal efficiency of MB and 4-NP by the membrane composed with three layers Au NPs/Wood exceeded 98.0\%. In addition, the $\mathrm{Au}$ NPs/Wood possessed good recyclability. Conclusively, the wood decorated with $\mathrm{Au}$ NPs has the advantages of high cost-effectiveness, biodegradability, simple preparation, green and pollution-free, and excellent catalytic activity.

\section{Acknowledgement}

This work was supported by the Natural Science Foundation of Guangxi (2018JJA130224), the Foundation of Guangxi Key Laboratory of Clean Pulp \& Papermaking and Pollution Control (ZR201805-7), and the Opening Project of National Enterprise Technology Center of Guangxi Bossco Environmental Protection 
Technology Co., Ltd, Nanning 530007, China.

\section{Conflict of interest}

353 The authors declare there is no conflict of interest.

\section{References}

Aditya, T., Pal, A., Pal, T., 2015. Nitroarene reduction: a trusted model reaction to test nanoparticle catalysts. Chem Commun (Camb) 51(46), 9410-9431.

Al-Johani, H., Abou-Hamad, E., Jedidi, A., Widdifield, C.M., Viger-Gravel, J., Sangaru,

Alba-Molina, D., Puente Santiago, A.R., Giner-Casares, J.J., Martín-Romero, M.T., M.J., El Eter, M., Cavallo, L., Emsley, L., Basset, J.M., 2017. The structure and binding mode of citrate in the stabilization of gold nanoparticles. Nat Chem 9(9), 890-895.

Camacho, L., Luque, R., Cano, M., 2019. Citrate-Stabilized Gold Nanoparticles as High-Performance Electrocatalysts: The Role of Size in the Electroreduction of Oxygen. The Journal of Physical Chemistry C 123(15), 9807-9812.

Amendola, V., Pilot, R., Frasconi, M., Marago, O.M., Iati, M.A., 2017. Surface plasmon resonance in gold nanoparticles: a review. J Phys Condens Matter 29(20), 203002.

Ates, S., Ni, Y., Akgul, M., Tozluoglu, A., 2008. Characterization and evaluation of Paulownia elongota as a raw material for paper production. African journal of biotechnology 7(22), 4153-4158.

Cabreira, C.R., Camilo, F.F., 2020. Evaluation of catalytic activity of cellulose films decorated with gold nanoparticles in the reduction of 4-nitrophenol. Cellulose 27(7), 3919-3929.

Chen, C., Kuang, Y., Zhu, S., Burgert, I., Keplinger, T., Gong, A., Li, T., Berglund, L., Eichhorn, S.J., Hu, L., 2020. Structure-property-function relationships of natural and engineered wood. Nature Reviews Materials 5(9), 642-666.

Cheng, M.-m., Huang, L.-j., Wang, Y.-x., Tang, J.-g., Wang, Y., Zhao, Y.-c., Liu, G.-f., Zhang, Y., Kipper, M.J., Wickramasinghe, S.R., 2018. Reduced graphene oxide- 
gold nanoparticle membrane for water purification. Separation Science and Technology 54(6), 1079-1085.

Gualteros, J.A.D., Garcia, M.A.S., da Silva, A.G.M., Rodrigues, T.S., Cândido, E.G., e Moura, C.V.R., Camargo, P.H.C., de Moura, E.M., 2018. Synthesis of highly dispersed gold nanoparticles on $\mathrm{A} 12 \mathrm{O} 3, \mathrm{SiO} 2$, and $\mathrm{TiO} 2$ for the solvent-free oxidation of benzyl alcohol under low metal loadings. Journal of Materials Science 54(1), 238-251.

Guo, R., Cai, X., Liu, H., Yang, Z., Meng, Y., Chen, F., Li, Y., Wang, B., 2019. In Situ Growth of Metal-Organic Frameworks in Three-Dimensional Aligned Lumen Arrays of Wood for Rapid and Highly Efficient Organic Pollutant Removal. Environ Sci Technol 53(5), 2705-2712.

Gupta, N., Singh, H.P., Sharma, R.K., 2011. Metal nanoparticles with high catalytic activity in degradation of methyl orange: An electron relay effect. Journal of Molecular Catalysis A: Chemical 335(1-2), 248-252.

Haiss, W., Thanh, N.T., Aveyard, J., Fernig, D.G., 2007. Determination of size and concentration of gold nanoparticles from UV - Vis spectra. Analytical chemistry $79(11), 4215-4221$.

Hassinen, J., Liljeström, V., Kostiainen, M.A., Ras, R.H.A., 2015. Rapid Cationization of Gold Nanoparticles by Two-Step Phase Transfer. Angewandte Chemie International Edition 54(27), 7990-7993.

Huang, R., Zhu, H., Su, R., Qi, W., He, Z., 2016. Catalytic Membrane Reactor Immobilized with Alloy Nanoparticle-Loaded Protein Fibrils for Continuous Reduction of 4-Nitrophenol. Environ Sci Technol 50(20), 11263-11273.

Jacob, H.-E., 1970. Chapter IV redox potential, Methods in microbiology. Elsevier, pp. 91-123.

Janjić, Z., Janjić, M., 2019. Paulownia, characteristics and perspectives of its exploitation. Innovation in Woodworking Industry and Engineering Design(2), 3441. 
Ji, T., Chen, L., Schmitz, M., Bao, F.S., Zhu, J., 2015. Hierarchical macrotube/mesopore carbon decorated with mono-dispersed Ag nanoparticles as a highly active catalyst. Green Chemistry 17(4), 2515-2523.

Ju, X., Bowden, M., Brown, E.E., Zhang, X., 2015. An improved X-ray diffraction method for cellulose crystallinity measurement. Carbohydr Polym 123, 476-481.

Kong, B.-S., Geng, J., Jung, H.-T., 2009. Layer-by-layer assembly of graphene and gold nanoparticles by vacuum filtration and spontaneous reduction of gold ions. Chemical Communications(16), 2174-2176.

Kong, L., Guo, Y., Wang, X., Zhang, X., 2020. Double-walled hierarchical porous silica nanotubes loaded Au nanoparticles in the interlayer as a high-performance catalyst. Nanotechnology 31(1), 015701.

Kumar, I., Mondal, M., Meyappan, V., Sakthivel, N., 2019. Green one-pot synthesis of gold nanoparticles using Sansevieria roxburghiana leaf extract for the catalytic degradation of toxic organic pollutants. Materials Research Bulletin 117, 18-27.

Liu, G., Chen, D., Liu, R., Yu, Z., Jiang, J., Liu, Y., Hu, J., Chang, S., 2019. Antifouling Wood Matrix with Natural Water Transfer and Microreaction Channels for Water Treatment. ACS Sustainable Chemistry \& Engineering 7(7), 6782-6791.

Liu, Y., Liu, X., Yang, S., Li, F., Shen, C., Huang, M., Li, J., Nasaruddin, R.R., Xie, J., 2018. Rational Design of High-Performance Continuous-Flow Microreactors Based on Gold Nanoclusters and Graphene for Catalysis. ACS Sustainable Chemistry \& Engineering 6(11), 15425-15433.

Liu, Y., Zheng, Y., Du, B., Nasaruddin, R.R., Chen, T., Xie, J., 2017. Golden Carbon Nanotube Membrane for Continuous Flow Catalysis. Industrial \& Engineering Chemistry Research 56(11), 2999-3007.

Luo, N., Wang, M., Li, H., Zhang, J., Hou, T., Chen, H., Zhang, X., Lu, J., Wang, F., 2017. Visible-Light-Driven Self-Hydrogen Transfer Hydrogenolysis of Lignin Models and Extracts into Phenolic Products. ACS Catalysis 7(7), 4571-4580.

Luty-Błocho, M., Fitzner, K., Hessel, V., Löb, P., Maskos, M., Metzke, D., Pacławski, K., Wojnicki, M., 2011. Synthesis of gold nanoparticles in an interdigital 
micromixer using ascorbic acid and sodium borohydride as reducers. Chemical Engineering Journal 171(1), 279-290.

Ma, M., Yang, Y., Li, W., Feng, R., Li, Z., Lyu, P., Ma, Y., 2018. Gold nanoparticles supported by amino groups on the surface of magnetite microspheres for the catalytic reduction of 4-nitrophenol. Journal of Materials Science 54(1), 323-334.

Massaro, M., Colletti, C.G., Fiore, B., La Parola, V., Lazzara, G., Guernelli, S., Zaccheroni, N., Riela, S., 2019. Gold nanoparticles stabilized by modified halloysite nanotubes for catalytic applications. Applied Organometallic Chemistry 33(3), e4665.

Neal, R.D., Inoue, Y., Hughes, R.A., Neretina, S., 2019. Catalytic Reduction of 4Nitrophenol by Gold Catalysts: The Influence of Borohydride Concentration on the Induction Time. The Journal of Physical Chemistry C, 12894-12901.

Nguyen, T.B., Huang, C.P., Doong, R.-a., 2019. Enhanced catalytic reduction of nitrophenols by sodium borohydride over highly recyclable Au@graphitic carbon nitride nanocomposites. Applied Catalysis B: Environmental 240, 337-347.

Plaza, N.Z., 2019. On the Experimental Assessment of the Molecular-Scale Interactions between Wood and Water. Forests 10(8), 616.

Qin, L., Yi, H., Zeng, G., Lai, C., Huang, D., Xu, P., Fu, Y., He, J., Li, B., Zhang, C., Cheng, M., Wang, H., Liu, X., 2019. Hierarchical porous carbon material restricted Au catalyst for highly catalytic reduction of nitroaromatics. J Hazard Mater 380, 120864.

Qin, L., Zeng, Z., Zeng, G., Lai, C., Duan, A., Xiao, R., Huang, D., Fu, Y., Yi, H., Li, B., Liu, X., Liu, S., Zhang, M., Jiang, D., 2019. Cooperative catalytic performance of bimetallic $\mathrm{Ni}-\mathrm{Au}$ nanocatalyst for highly efficient hydrogenation of nitroaromatics and corresponding mechanism insight. Applied Catalysis B: Environmental 259, 118035.

Quast, A.D., Bornstein, M., Greydanus, B.J., Zharov, I., Shumaker-Parry, J.S., 2016. Robust Polymer-Coated Diamond Supports for Noble-Metal Nanoparticle Catalysts. ACS Catalysis 6(7), 4729-4738. 
Ramirez, O., Bonardd, S., Saldias, C., Radic, D., Leiva, A., 2017. Biobased Chitosan Nanocomposite Films Containing Gold Nanoparticles: Obtainment, Characterization, and Catalytic Activity Assessment. ACS Appl Mater Interfaces 9(19), 16561-16570.

Raveendran, P., Fu, J., Wallen, S.L., 2003. Completely "green" synthesis and stabilization of metal nanoparticles. Journal of the American Chemical Society 125(46), 13940-13941.

Saini, G., Jensen, D.S., Wiest, L.A., Vail, M.A., Dadson, A., Lee, M.L., Shutthanandan, V., Linford, M.R., 2010. Core-Shell Diamond as a Support for Solid-Phase Extraction and High-Performance Liquid Chromatography. Analytical chemistry $82(11), 4448-4456$.

Sharma, N., Ojha, H., Bharadwaj, A., Pathak, D.P., Sharma, R.K., 2015. Preparation and catalytic applications of nanomaterials: a review. RSC Advances 5(66), 53381-53403.

Shultz, L.R., Hu, L., Preradovic, K., Beazley, M.J., Feng, X., Jurca, T., 2019. A Broaderscope Analysis of the Catalytic Reduction of Nitrophenols and Azo Dyes with Noble Metal Nanoparticles. ChemCatChem 11(11), 2590-2595.

Singh, B.K., Lee, S., Na, K., 2019. An overview on metal-related catalysts: metal oxides, nanoporous metals and supported metal nanoparticles on metal organic frameworks and zeolites. Rare Metals 39(7), 751-766.

Thomas, R., 1977. Wood: Structure and chemical composition, Wood Technology: Chemical Aspects, Chapter 1, pp 1-23.

Unal, I.S., Demirbas, A., Onal, I., Ildiz, N., Ocsoy, I., 2020. One step preparation of stable gold nanoparticle using red cabbage extracts under UV light and its catalytic activity. J Photochem Photobiol B 204, 111800.

Wang, C., Zhang, K., Xu, H., Du, Y., Goh, M.C., 2019. Anchoring gold nanoparticles on poly(3,4-ethylenedioxythiophene) (PEDOT) nanonet as three-dimensional electrocatalysts toward ethanol and 2-propanol oxidation. J Colloid Interface Sci $541,258-268$. 
Wang, J., Deng, Y., Qian, Y., Qiu, X., Ren, Y., Yang, D., 2016. Reduction of lignin color via one-step UV irradiation. Green Chemistry 18(3), 695-699.

Wang, X., Fu, J., Wang, M., Wang, Y., Chen, Z., Zhang, J., Chen, J., Xu, Q., 2014. Facile synthesis of Au nanoparticles supported on polyphosphazene functionalized carbon nanotubes for catalytic reduction of 4-nitrophenol. Journal of Materials Science 49(14), 5056-5065.

Yan, L., Zhang, T., Lei, W., Xu, Q., Zhou, X., Xu, P., Wang, Y., Liu, G., 2014. Catalytic activity of gold nanoparticles supported on $\mathrm{KNbO}_{3}$ microcubes. Catalysis Today $224,140-146$.

Yan, Z., Fu, L., Zuo, X., Yang, H., 2018. Green assembly of stable and uniform silver nanoparticles on 2D silica nanosheets for catalytic reduction of 4-nitrophenol. Applied Catalysis B: Environmental 226, 23-30.

Zahmakiran, M., Ozkar, S., 2011. Metal nanoparticles in liquid phase catalysis; from recent advances to future goals. Nanoscale 3(9), 3462-3481.

Zhang, F., Zhao, X., Feng, C., Li, B., Chen, T., Lu, W., Lei, X., Xu, S., 2011. CrystalFace-Selective Supporting of Gold Nanoparticles on Layered Double Hydroxide as Efficient Catalyst for Epoxidation of Styrene. ACS Catalysis 1(4), 232-237.

Zhang, Q.-P., Sun, Y.-1., Cheng, G., Wang, Z., Ma, H., Ding, S.-Y., Tan, B., Bu, J.-h., Zhang, C., 2020. Highly dispersed gold nanoparticles anchoring on post-modified covalent organic framework for catalytic application. Chemical Engineering Journal 391, 123471.

Zhu, M., Li, Y., Chen, F., Zhu, X., Dai, J., Li, Y., Yang, Z., Yan, X., Song, J., Wang, Y., Hitz, E., Luo, W., Lu, M., Yang, B., Hu, L., 2018. Plasmonic Wood for HighEfficiency Solar Steam Generation. Advanced Energy Materials 8(4), 1701028. 


\section{Figures}

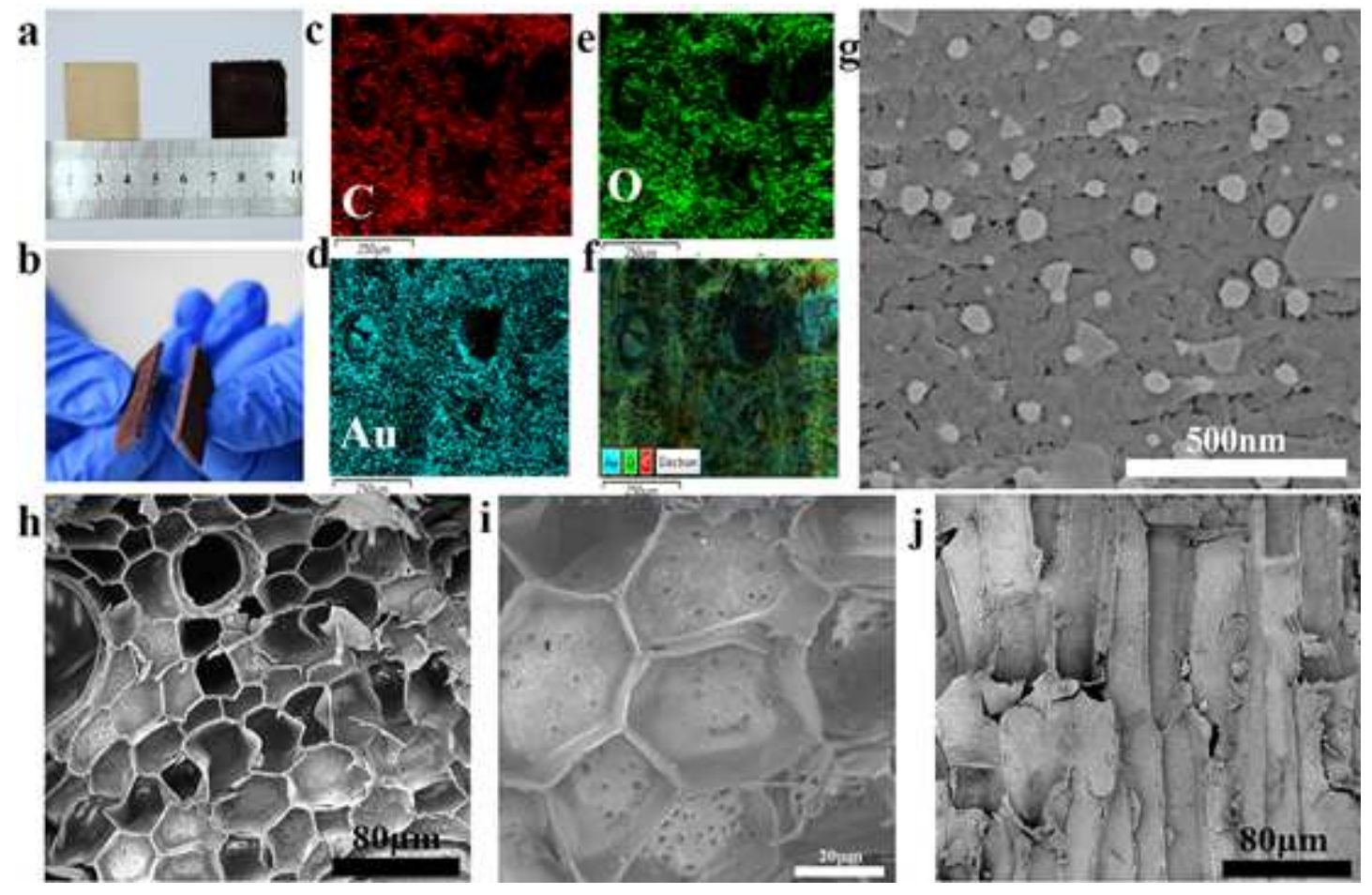

Figure 1

Photos of (a) the wood and (b) the Au NPs/Wood. (c)-(f) C, O, Au elemental mapping of a transverse section of the Au NPs/Wood. (g) SEM image of Au NPs distributing on the wood. (h-j) SEM images of the Au NPs/Wood. 

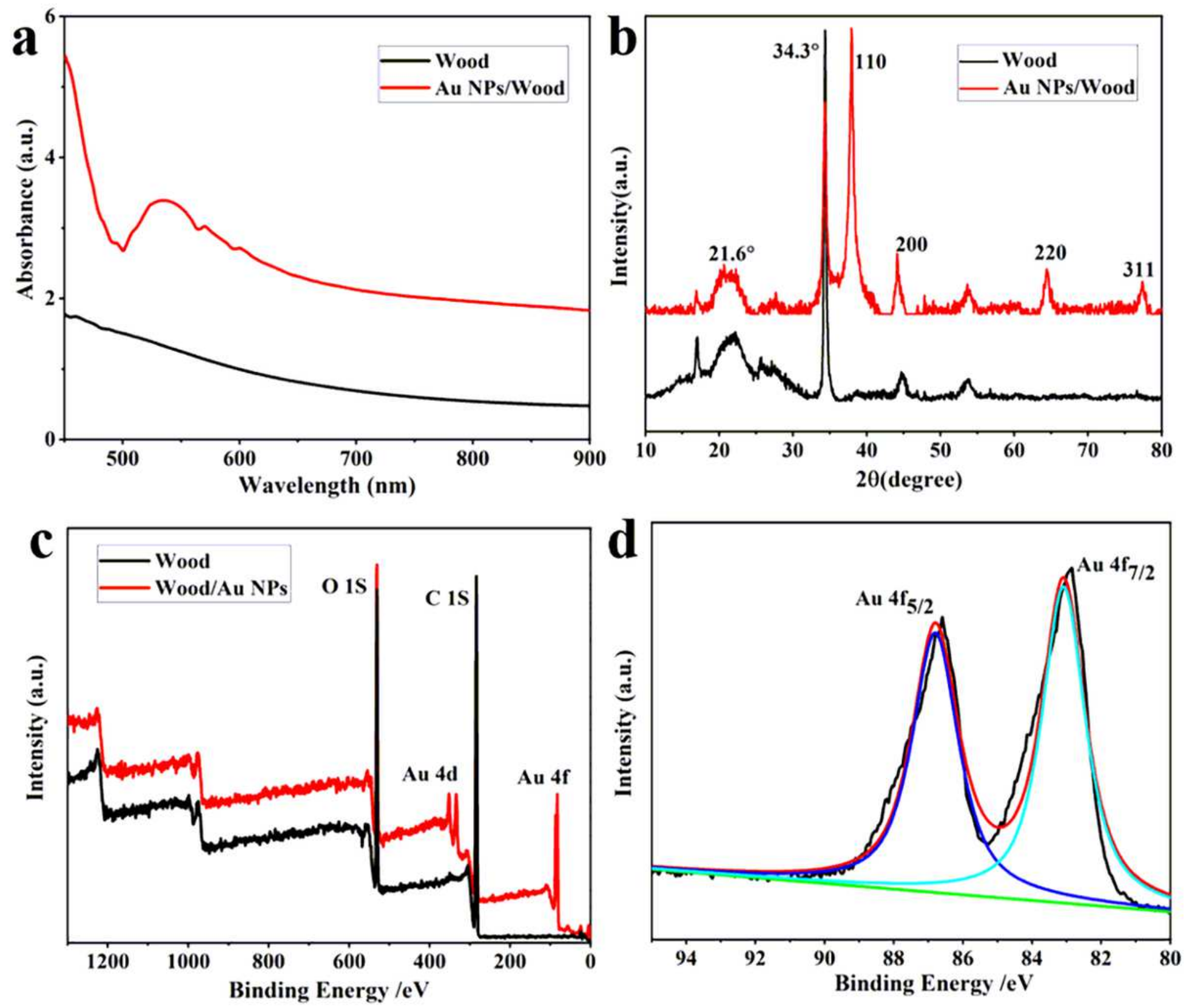

Figure 2

(a) UV-Vis spectrum of the wood and the Au NPs/Wood. (b) XRD patterns of the wood and the Au NPs/Wood. (c) XPS of the wood and the Au NPs/Wood, and (d) high-resolution XPS spectra of Au $4 \mathrm{f}$ in the Au NPs/Wood. 

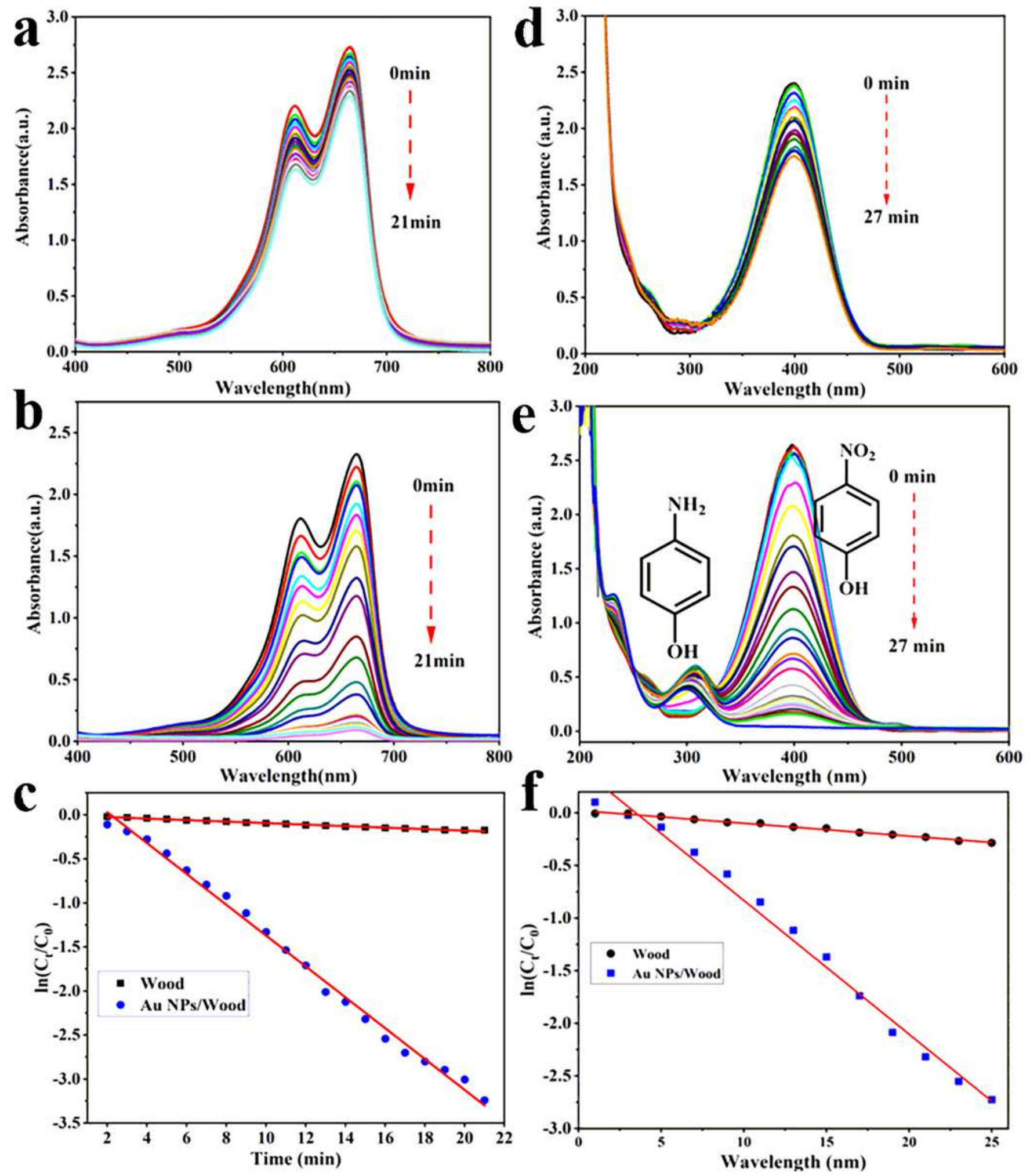

Figure 3

The successive spectra of the mixture of $\mathrm{MB}$ and $\mathrm{NaBH} 4$ from 400 to $800 \mathrm{~nm}$ of (a) the wood and (b) the Au NPs/Wood. (c) The curve of $\ln (\mathrm{Ct} / \mathrm{CO})$ with reaction time and the quasi-first-order kinetic fitting of wood and Au NPs/Wood. The successive spectra of the mixture of NaBH4 and 4-NP from 200 to $600 \mathrm{~nm}$ of (d) the wood and (e) the Au NPs/Wood. (f) The curve of $\ln (\mathrm{Ct} / \mathrm{CO})$ with reaction time and the quasifirst-order kinetic fitting of wood and Au NPs/Wood. 

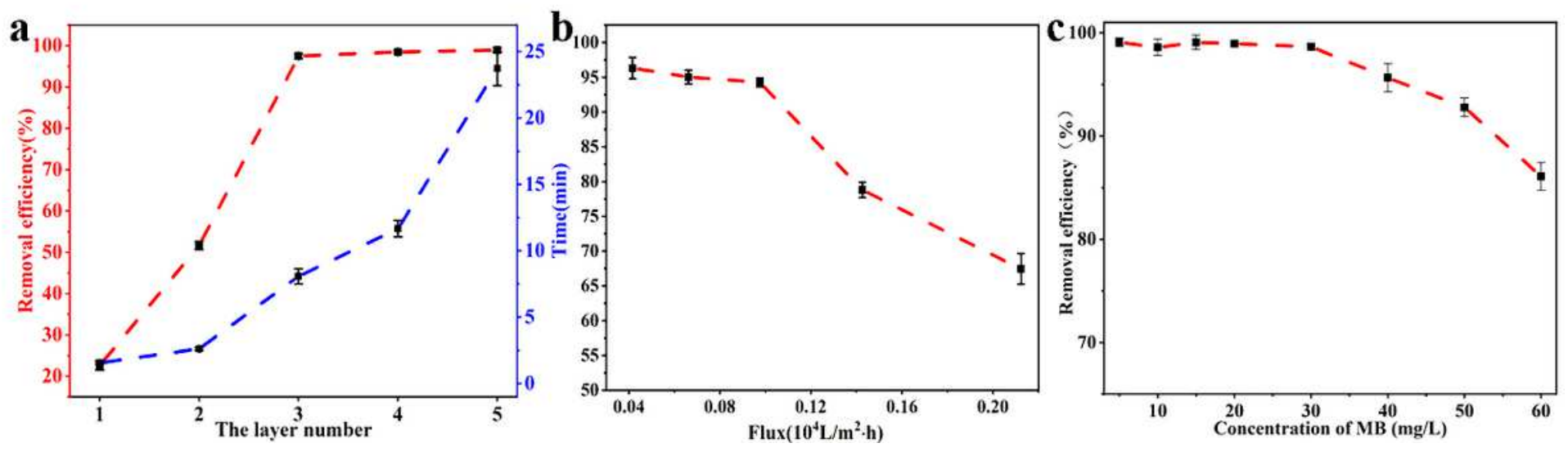

Figure 4

(a) The layer number of Au NPs/Wood impacting on the removal efficiency and filtration time. (b) The correlation between the removal efficiency and the water flux. (c) The relationship between the removal efficiency and MB concentration.
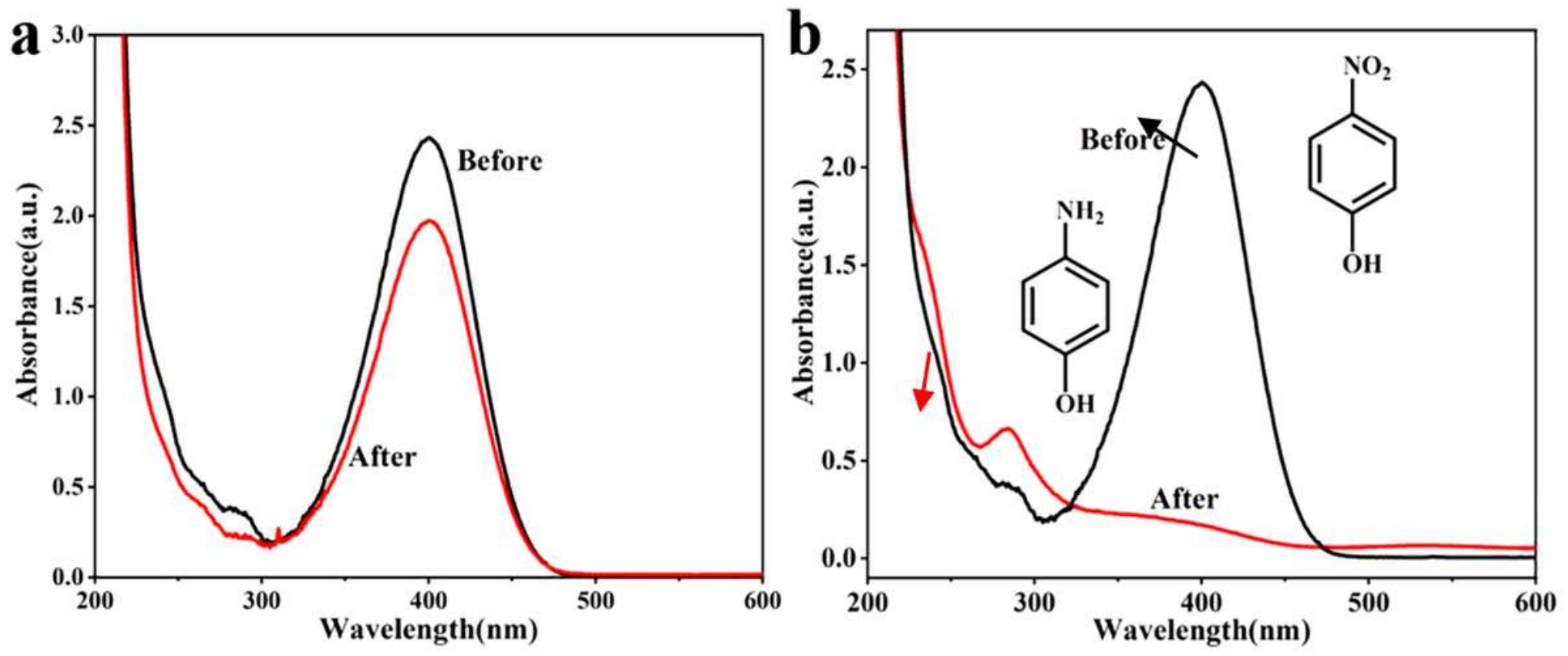

Figure 5

The UV-Vis absorption change of 4-NP during the filtration through the wood (a) and the Au NPs/Wood (b). 

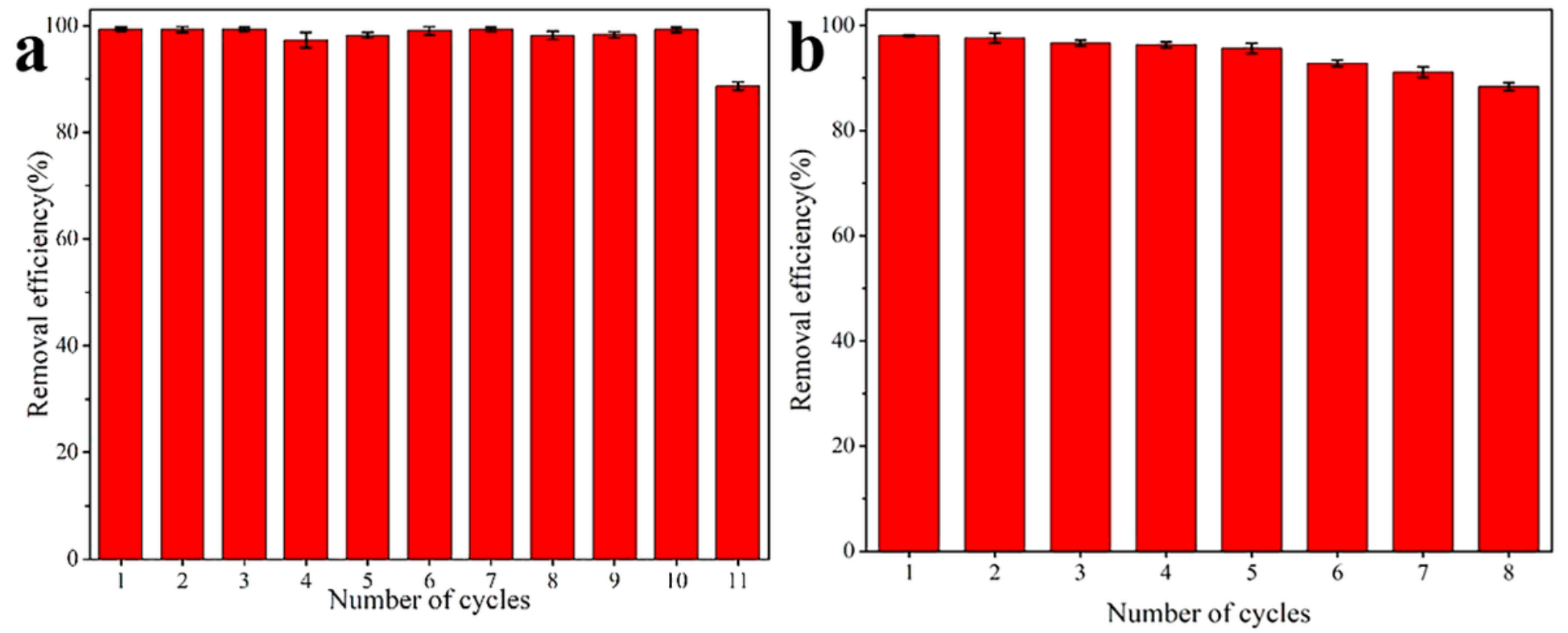

Figure 6

The recyclability of the Au NPs/Wood for catalytic reduction of MB (a) and 4-NP (b).

\section{Supplementary Files}

This is a list of supplementary files associated with this preprint. Click to download.

- SupportinginformationV6.docx 